\title{
One-child Ideation in India
}

Stuart Gietel-Basten, The Hong Kong University of Science and Technology, Hong Kong SAR

Mamta Rajbhar, Evidence Action, India

Pre-print: February $28^{\text {th }} 2018$

\begin{abstract}
India has seen a truly remarkable transition towards lower fertility over recent decades. The country is on course to reach replacement level fertility by 2020 . Yet, there is a large degree of variation between states. In some areas, for example, total fertility rates are as low as 1.6 or 1.7 .

Profound changes in fertility preferences have accompanied this fertility transition. In particular, there has been a strong shift towards a two-child norm. In recent years, however, there has been developing evidence of a growing ideation towards having just one-child. This phenomenon has been associated with the rise of the Indian middle class and has been the subject of some attention in both academic and popular circles.

Using evidence from th National Family Health Survey, this chapter explores this phenomenon in the Indian context. In doing so, we explore the possible implications both for the future direction of fertility transition in India, as well as for the family as an institution.
\end{abstract}

Keywords: India, one-child family, fertility, West Bengal, families, family size 


\section{One-child Ideation in India}

\section{Low fertility and ideation of one-child: A new phenomenon?}

India is increasingly gaining attention as a site of study for one-child families and their ideation. In this paper, we explore recent trends and determinants of the prevalence of onechild families, with a primary concentration on the use of the Indian Demographic and Health Survey equivalent, namely the National Family Health Survey [NFHS]. This is a nationally representative cross-sectional survey with rounds conducted in 1992-93, 1998-99, and 200506. The first two surveys had sample sizes of around 90,000 ever married women while the 2005-06 survey saw an increased sample size of around 125,000. Pradhan and Sekher (2014) have analyzed the various rounds of the NFHS to identify levels and trends of single-child families in India and we draw on their analysis here. We first explore trends among women who have completed their reproductive life, which here is deemed to be ever married women aged 45-49 and ever married women aged 15-44 who are sterilized or whose husbands are sterilized. Finally, we make some brief observations about the 'at-risk' population at younger ages.

Among this group of women, the overall proportion of single-child families is certainly low (3.9 per cent in 2005-06) and has only increased modestly over time (up from 3.4 per cent in 1992-93 and 3.1 per cent in 1998-99). However, this masks important differentials. First, in urban areas in 2005-06 the rate was 4.6 per cent compared to 3.5 per cent in rural areas. When factoring in regional differences, however, the difference became larger still. In rural Maharashtra, the rate is just 2.9 per cent - or less than 1:30 - while in urban Karnataka, Andhra Pradesh, Tamil Nadu, and Odisha the proportions are between 5.2 per cent and 6.4 per cent. These generally southern states include cities such as Bengaluru, Hyderabad, Visakhapatnam, Chennai, and Bhubaneswar.

In urban West Bengal, meanwhile, the proportion is 9.8 per cent. Upon inspection of infant and adult mortality rates for West Bengal from the sample Registration System, we can see that this phenomenon is unlikely to be mortality driven, given the low death rates in the state. Despite being a northern state (which are generally characterized by rather higher fertility), urban West Bengal (and especially its largest city, Kolkata) has been a forerunner in terms of fertility decline (Bhat, 1996). Indeed, Kolkata has the lowest fertility rate of all districts in India - estimated in 2011 to be just 1.2 (Guilmoto \& Rajan, 2013) - and the 
highest number of one-child families in the country . This has led to much discussion about the question "Where have Bengal's babies gone?" as the Times of India provocatively titled an article on the state in 2012 (Sen, 2012).

In terms of other characteristics of the differential proportions of one-child family prevalence among women who have completed their reproductive life in 2005-06 beyond a rural/urban and regional dimension, we see higher proportions among women with greater exposure to mass media [Yes 4.1 per cent, $\mathrm{N}=30,486$ cf. No 3.1 per cent, $\mathrm{N}=6,968$ ]; with higher education ['high' level of education 6.7 per cent, $\mathrm{N}=3,949$; 'medium' 3.8 per cent, $\mathrm{N}=13,585$; 'low' 3.7 per cent, $\mathrm{N}=19,969$ ], Christian women [6.1 per cent, $\mathrm{N}=2,176$; cf. Hindu 3.9 per cent, $N=30,331$; Muslim 2.9 per cent, 3,491; 'others' 3.1 per cent, $N=1,816$ ] and among women engaged in professional or service-sector employment [5.7 per cent, $\mathrm{N}=$ 4,572; cf. 'agriculture and manual' 3.7 per cent, $\mathrm{N}=13,590$; and 'not working' 3.7 per cent, $\mathrm{N}=19,652]$. Unsurprisingly, the proportion of women who married or had their first birth at a later age (deemed as over 27) with one child is much higher than those who married or gave birth at earlier ages.

As noted earlier, however, upon splitting the sample into smaller and smaller subgroups it is important to perform some basic regression analyses to confirm the validity of these proportions. Pradhan and Sekher ran three logistic regression models to further examine the determinants of single-child families across India. Their first model examined the effects of household factors, and showed that rural residence and Muslim religion is negatively correlated to having a one-child family $(\mathrm{p}<0.001)$. In Model 2 , which looks at the effect of individual characteristics, women's age at childbirth, couples' education, and women's occupation have a statistically significant effect on the odds of single-child families. Finally, Model 3, which controls for all of the factors described in Models 1 and 2, found that for the pooled data from three rounds, place of residence, religion, caste, economic status of households, women's age at childbirth, and women's and husband's occupation are significant predictors of having a single child. This leads them to conclude that 'The urban, rich, employed women and women who marry at a later age are likely to have single-child families' (Pradhan and Sekher, 2014, p. 169).

The findings from the NFHS are generally echoed in studies of another large-scale Indian survey, namely the India Human Development Survey [IHDS]. This is a nationally representative sample survey conducted in 2004-05, with a sample of 33,524 women with a complete fertility history analyzed by Basu and Desai (2012). Their mode of analysis, however, is slightly different. Rather than focusing on women who are no longer able to 
reproduce, they examine women who are still in their reproductive years but appeared to have stopped at one child. If there is a gap of more than five years between first birth and point of survey they assume that this couple has appeared to stop childbearing. This is based upon the fact that in the IHDS data over 90 per cent of respondents with more than one birth reported a gap of less than five years between their first and second child being born. Addressing concerns (raised above) around ideation, and observing the possibility of involuntary sterility, Basu and Desai observe that some 94 per cent of couples began their childbearing in 'peak reproductive period', i.e., below age 30 (p. 11). Later in this paper we explore certain elements of Basu and Desai's analysis of the IHDS insofar as it relates to exploring the motivation to limit childbearing. In this discussion, meanwhile, we simply limit the focus to the characteristics of this group which they have identified as being likely to have limited their childbearing at one child and, as such, might be considered at best de facto, or at least pseudo one-child families. we refer to them as such here.

In line with evidence from the IFHS, a much greater proportion of Basu and Desai's pseudo one-child families are resident in urban areas, and in 'metropolitan areas' (population of greater than one million) in particular. Indeed, 13 per cent of included respondents to the survey were in pseudo one-child families in such metropolitan areas compared to 6 per cent in 'other urban' areas, 5 per cent in 'developed villages' and 4 per cent in 'less developed villages'. By state, just 1 per cent of respondents in Bihar, Uttarkhand, and Jammu and Kashmir were in pseudo one-child families compared to 10 per cent in Assam and 12 per cent in West Bengal (see Box 1 for Kolkata). Education levels, too, are positively related to a greater proportion of pseudo one-child families, with 16 per cent of college graduates in pseudo one-child families, 12 per cent for 'Year 12 and some college', falling to just 3 per cent for no education. Finally, the proportion of the richest quintile stated as pseudo one-child families was 8 per cent compared to between 4 per cent and 5 per cent for the lowest income quintiles. The statistical models employed by Basu and Desai are explored in greater depth later in this paper.

The recent study by Senthil Velou, Senthamizselvi, Teli, Soundarya, and Thendral (2014), set in Puducherry State, took a different approach to the measurement of one-child families by taking the children themselves as the primary object of observation rather than their parents. Here, first year engineering students at a local university were asked about the number of siblings they had as well as a series of questions relating to their social and economic background and a Depression Anxiety Stress Scales questionnaire for assessing 'negative emotional states'. Temporarily setting aside the many methodological limitations of 
this particular study (selection bias, confounding effects, small $\mathrm{N}$ of 289), we report the main findings here. Of the 289 respondents, 9.3 per cent were only children (and given their age were unlikely to be joined by a younger sibling in the future). Using Fisher's exact test, the authors found statistically significant associations between parents' (especially mothers') education, female employment, and one-child families. While we return to this study later in this paper, it is useful to cite this study here because of its relative novelty in terms of 'measuring' one-child families in a particular setting, and also for its novelty in studying the phenomenon in India at all.

Finally, in this section we can briefly explore the 'at risk population' who currently have one child and are thus demographically incomplete families. Figure 1, taking data from the latest IHDS, shows the parity distribution among married women at different ages. Among women aged 20-24, 18.6 per cent currently have no children while 33.2 per cent have one child; for women aged 25-29, the respective figures are 6.6 per cent and 15.8 per cent; finally, for women aged 30-34 the figures are 3.2 per cent and 8.3 per cent.

Figure 1: Completed and incomplete family sizes: married women by age group and number of children. India, 2005-2006

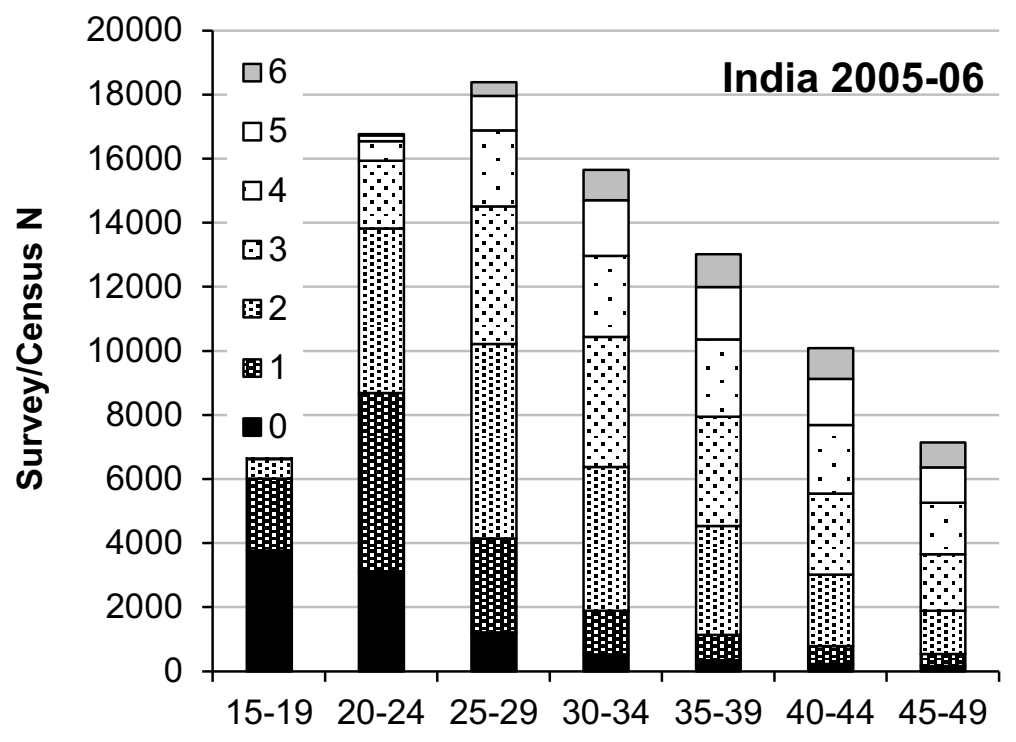

Source: DHS StatCompiler

Evidence from the 2005-06 National Family Health Survey 
In this following section, co-written with Mamta Rajbhar, we explore fertility preferences for India using the 2005-06 National Family Health Survey (known as NFHS-3); with a special emphasis on one-child families. NFHS-3 is the Indian equivalent of the Demographic and Health Surveys which are used in many developing countries to provide estimates of indicators of population, health, and nutrition by various background characteristics. It is a household survey, conducting interviews with women aged 15-49 and men aged 15-54. Fieldwork was carried out between December 2005 and August 2006, and interviews with more than 230,000 men and women were conducted. As the name implies, it is the third such survey, with earlier ones held in 1992-93 (NFHS-1) and 1998-99 (NFHS-2). Fieldwork for NFHS-4 was conducted in 2014-15, but the data are not yet available (see ${ }^{1}$ for details of the data); NFHS-3 is the latest available data to be analyzed. In particular, given the transitional status of Indian fertility, in this section we particularly want to think about younger groups who have either just started childbearing, or who are about to enter their reproductive careers, and to consider those who we might see becoming an ever greater feature of Indian society, namely more educated, urban populations. we hesitate to use the terms 'demographic vanguard' here or, even more contested, the notion of the 'middle class'. However, under certain visions of the future such groups might be considered as playing a greater role in the demographic future of India.

The NFHS-3 included a question asking couples their ideal family size, both in a prospective and hypothetical retrospective sense. In this survey, if a woman or man had living children, he/she was asked: "If you could go back to the time you did not have any children and could choose exactly the number of children to have in your whole life, how many would that be?" If, however, he or she did not have any living children, the question was: "If you could choose exactly the number of children to have in your whole life, how many would that be?" In addition to these two questions, one question related to the sex composition of the ideal family size was asked: "How many of these children would you like to be boys, how many you would like to be girls and how many would the sex not matter?"

Nationally, the ideal number of children across India declined from almost three when NFHS-1 was taken in 1992-93 to 2.4 by 2005-06 (NFHS-3). Table 1 presents summary descriptive statistics of responses where an ideal family size of two children or fewer was given. From the data in the table it is possible to see a very clear general preference for limiting childbearing to two or fewer children across India. As one might expect, there are

\footnotetext{
${ }^{1}$ (NFHS 2014).
} 
clear gradations by wealth and education, with 90 per cent of the richest and best educated unmarried men and women desiring a family size of two or fewer children. Furthermore, these gradations by education and wealth are not especially skewed towards the higher end of the scale, with moderate increases from 'poorest' to 'poor' and 'no education' to a small amount of education producing dramatic increases in small family preference.

Table 1: Ideation of small ( $\leq 2$ children) family sizes, never married and currently married men and women, India, 2005-06

\begin{tabular}{|c|c|c|c|c|c|c|c|c|}
\hline & \multirow{2}{*}{\multicolumn{2}{|c|}{$\begin{array}{l}\text { Never Married } \\
\% \text { Women }\end{array}$}} & & & \multicolumn{4}{|c|}{ Currently Married } \\
\hline & & & \multicolumn{2}{|l|}{ \% Men } & \multicolumn{2}{|c|}{ \% Women } & \multicolumn{2}{|l|}{ \% Men } \\
\hline & IFS $\leq 2$ & $\mathbf{N}$ & IFS $\leq 2$ & $\mathbf{N}$ & IFS $\leq 2$ & $\mathbf{N}$ & IFS $\leq 2$ & $\mathbf{N}$ \\
\hline India & 82.1 & 30,661 & 80.9 & 28,486 & 64.3 & 87,925 & 64.3 & 74,369 \\
\hline \multicolumn{9}{|l|}{ Age } \\
\hline$<30$ years & 82.5 & 29,334 & 81.0 & 26,493 & 70.2 & 36,966 & 69.8 & 36,595 \\
\hline $30+$ years & 67.5 & 1,327 & 78.1 & 1,993 & 59.4 & 50,595 & 62.6 & 37,774 \\
\hline \multicolumn{9}{|l|}{ Place of Residence } \\
\hline Urban & 89.3 & 16,002 & 86.4 & 13,637 & 76.7 & 38,382 & 73.8 & 38,199 \\
\hline Rural & 77.1 & 14,659 & 76.7 & 9,184 & 58.8 & 49,543 & 59.6 & 36,170 \\
\hline \multicolumn{9}{|l|}{ Wealth Index } \\
\hline Poorest & 64.2 & 2,036 & 63.2 & 1,165 & 43.0 & 11,138 & 43.9 & 7,085 \\
\hline Poorer & 73.5 & 3,233 & 74.2 & 2,332 & 55.3 & 13,417 & 55.8 & 10,278 \\
\hline Middle & 81.5 & 5,597 & 79.8 & 4,203 & 65.1 & 16,800 & 64.6 & 14,865 \\
\hline Richer & 85.8 & 8,148 & 84.6 & 6,495 & 72.6 & 20,607 & 71.9 & 19,346 \\
\hline Richest & 90.9 & 11,647 & 89.1 & 8,626 & 82.9 & 25,963 & 81.3 & 22,795 \\
\hline \multicolumn{9}{|l|}{ Caste } \\
\hline Schedule Caste & 82.1 & 4,583 & 82.1 & 20,436 & 60.7 & 14,669 & 66.0 & 63,196 \\
\hline Schedule Tribe & 70.6 & 4,748 & 68.7 & 1,475 & 48.4 & 10,815 & 46.8 & 8,431 \\
\hline Other Backward Classes & 81.8 & 8,717 & 69.6 & 625 & 62.4 & 28,621 & 59.6 & 2,032 \\
\hline Other & 85.5 & 10,913 & 76.3 & 275 & 73.7 & 30,057 & 59.2 & 682 \\
\hline \multicolumn{9}{|l|}{ Religion } \\
\hline Hindu & 85.5 & 20,472 & 83.9 & 20,139 & 67.0 & 65,353 & 66.6 & 54,723 \\
\hline Muslim & 67.5 & 4,508 & 63.3 & 4,057 & 44.7 & 11,507 & 46.5 & 9,583 \\
\hline Christian & 70.9 & 3,791 & 69.9 & 2,905 & 67.5 & 6,565 & 62.1 & 6,651 \\
\hline Sikh & 82.5 & 717 & 85.8 & 394 & 80.0 & 1,950 & 79.4 & 1,010 \\
\hline
\end{tabular}




\begin{tabular}{lllllllll} 
Other & 81.1 & 1,136 & 86.2 & 986 & 68.3 & 2,438 & 66.5 & 2,388 \\
Education & & & & & & & & \\
No education & 53.9 & 2,792 & 56.3 & 1,779 & 46.9 & 34,108 & 45.0 & 10,696 \\
$<5$ years completed & 71.1 & 874 & 59.8 & 900 & 65.3 & 4,225 & 55.3 & 4,220 \\
5-7 years completed & 78.9 & 4,500 & 73.7 & 4,212 & 73.7 & 13,511 & 63.8 & 11,895 \\
8-9 years completed & 86.2 & 7,625 & 81.7 & 7,383 & 81.5 & 11,799 & 68.3 & 15,613 \\
10-11 years completed & 88.4 & 6,050 & 87.2 & 5,825 & 86.7 & 8,948 & 76.5 & 11,860 \\
12 or more years completed & 92.9 & 8,054 & 92.0 & 7,617 & 92.5 & 12,166 & 83.8 & 17,334 \\
\hline
\end{tabular}

Source: NFHS-3, 2005-06 
In terms of a view of the future, we might however consider the preferences of never married women (and men) aged under 30 whose preferences might be better characterized as 'ideals' because they do not yet have children. As Table 1 shows, this group, across the various sets of social and economic characteristics, overwhelmingly have an ideal family size of two or fewer. We also identify a stronger preference in urban settings where there is a very strong preference for having two or fewer children, especially among the young never married. Because of the marriage structure in India, the never married are overwhelmingly young women $($ aged $<30)$. Given that this younger unmarried generation will have entered their reproductive careers by now and will therefore be instrumental in shaping future patterns of fertility in India, understanding the demographic dynamics of this group is critical. Furthermore, as India becomes increasingly urbanized, this 'town effect' could also become highly significant.

As Table 2 demonstrates, there are also significant differences by state. Despite this, all but five of the states show a majority of unmarried women reporting a preference for families with two children or less. There is, however, rather an imperfect correlation between a state's total fertility rate and the ideation of small families. While Himachal Pradesh, Punjab, and Delhi are indeed in the lowest quartile for fertility in India and associated with strong ideation of small families, Kerala and Tamil Nadu are also in the lowest quartile for TFR but simultaneously are in the lowest quartile for small family size ideation. In this section, we have shown that young Indian women generally aspire to have two or fewer children. If we examine certain subgroups, namely urban women, richer women, and better educated women, we see the proportion being very high indeed. In this sense, therefore, the notion of an ideal ceiling of two children appears to be just as much in evidence in much of India as it is in the other Asian settings considered elsewhere; we will return to this point later.

Table 2: Ideation of small ( $\leq 2$ children) family sizes, never married and currently married men and women, states of India, 2005-06

\begin{tabular}{|c|c|c|c|c|c|}
\hline \multirow{3}{*}{ States } & \multirow{2}{*}{$\begin{array}{r}\text { Never Married } \\
\% \text { Women }\end{array}$} & & & \multicolumn{2}{|c|}{ Currently Married } \\
\hline & & & & \% Women & $\%$ Men \\
\hline & IFS $\leq 2$ & IFS $\leq 2$ & $\mathbf{N}$ & $I F S \leq 2 \quad N$ & IFS $\leq 2 \quad N$ \\
\hline
\end{tabular}




\begin{tabular}{|c|c|c|c|c|c|c|c|c|}
\hline India & 82.1 & 30,661 & 80.9 & 28,486 & 64.3 & 87,925 & 64.3 & 74,369 \\
\hline Himachal Pradesh & 97.0 & 1,311 & 95.0 & 2,120 & 91.0 & 4,183 & 87.8 & 5,696 \\
\hline Punjab & 94.3 & 704 & 86.5 & 329 & 86.0 & 1,337 & 75.6 & 810 \\
\hline Uttaranchal & 92.0 & 840 & 95.6 & 410 & 90.1 & 2,255 & 88.0 & 1,067 \\
\hline Haryana & 91.3 & 892 & 87.8 & 623 & 79.5 & 2,352 & 81.1 & 1,436 \\
\hline Delhi & 90.6 & 1,527 & 89.4 & 2,659 & 79.7 & 5,153 & 77.4 & 7,128 \\
\hline Rajasthan & 90.5 & 782 & 88.9 & 360 & 69.2 & 2,074 & 77.3 & 983 \\
\hline Uttar Pradesh & 88.5 & 2,221 & 86.3 & 3,658 & 75.6 & 6,329 & 71.9 & 8,867 \\
\hline Bihar & 87.3 & 1,280 & 87.7 & 2,034 & 78.4 & 4,354 & 75.9 & 5,528 \\
\hline Sikkim & 86.8 & 451 & 90.9 & 275 & 80.3 & 1,336 & 75.9 & 711 \\
\hline Arunachal Pradesh & 86.4 & 1,429 & 85.0 & 1,003 & 80.3 & 4,973 & 77.0 & 2,669 \\
\hline Nagaland & 86.2 & 1,223 & 82.8 & 903 & 54.1 & 4,923 & 50.7 & 2,725 \\
\hline Manipur & 86.0 & 1,097 & 88.4 & 545 & 65.2 & 3,260 & 69.7 & 1,592 \\
\hline Mizoram & 85.9 & 1,171 & 83.5 & 522 & 77.0 & 2,136 & 75.5 & 1,185 \\
\hline Tripura & 84.2 & 699 & 77.0 & 433 & 49.6 & 3,044 & 47.9 & 1,471 \\
\hline Jammu and Kashmir & 83.0 & 1,162 & 71.3 & 505 & 60.8 & 2,044 & 57.5 & 1,076 \\
\hline Meghalaya & 80.6 & 1,000 & 73.3 & 587 & 63.1 & 2,631 & 64.7 & 1,394 \\
\hline Assam & 80.5 & 924 & 84.4 & 505 & 75.4 & 2,634 & 76.2 & 1,329 \\
\hline West Bengal & 78.3 & 768 & 79.1 & 434 & 68.4 & 2,829 & 64.3 & 1,428 \\
\hline Jharkhand & 75.9 & 796 & 75.7 & 437 & 66.9 & 2,617 & 70.8 & 1,121 \\
\hline Orissa & 75.5 & 539 & 86.0 & 384 & 68.6 & 2,134 & 72.3 & 1,083 \\
\hline Chhattisgarh & 75.4 & 843 & 70.4 & 424 & 43.4 & 2,724 & 52.9 & 1,384 \\
\hline Madhya Pradesh & 74.1 & 2,866 & 72.0 & 4,239 & 46.0 & 8,973 & 50.8 & 11,458 \\
\hline Gujarat & 73.5 & 557 & 76.1 & 317 & 48.8 & 2,295 & 42.2 & 996 \\
\hline Maharashtra & 68.0 & 703 & 64.0 & 402 & 44.7 & 2,992 & 45.1 & 1,214 \\
\hline Andhra Pradesh & 59.7 & 1,650 & 58.7 & 1,676 & 35.5 & 2,662 & 36.4 & 3,951 \\
\hline Karnataka & 49.8 & 455 & 53.0 & 265 & 36.8 & 1,127 & 38.8 & 711 \\
\hline Goa & 39.1 & 1,405 & 34.1 & 1,823 & 22.7 & 2,329 & 21.3 & 3,971 \\
\hline Kerala & 35.7 & 776 & 30.6 & 344 & 17.8 & 1,168 & 17.1 & 720 \\
\hline Tamil Nadu & 13.9 & 590 & 8.9 & 270 & 6.5 & 1,057 & 5.4 & 665 \\
\hline
\end{tabular}

Source: NFHS-3, 2005-06

Returning to the two questions asked in the survey and outlined above, Table 3 shows the percentage of married and never married women who stated an ideal family size of one child. Perhaps surprisingly, 17 per cent of never married women stated that their ideal family 
size was just one child. Importantly, however, there appears to be a strong link between urban residence, wealth, and education, with increased tendency towards an ideal family size of one child. Indeed, the descriptive analysis shows that the most educated women are nine times more likely to state an ideal family size of one compared to the least educated, while the richest women are six times more likely than the poorest to prefer one child. In terms of caste distinction, reported preferences for one-child families is lowest among Standard Tribe women and men, and by religion it is noticeably lower among Muslims. A similar pattern exists among currently married men and women, except that one-child ideation is higher among younger rather than older men and women, despite the overall levels being much lower compared to the never married.

Table 3: Percentage of never married and currently married women (15-49) and men (15-54) with an ideal family size of one child [IFS=1] by selected characteristics

\begin{tabular}{|c|c|c|c|c|c|c|c|c|}
\hline & \multirow{2}{*}{\multicolumn{2}{|c|}{$\begin{array}{l}\text { Never Married } \\
\text { Women }\end{array}$}} & \multirow{2}{*}{\multicolumn{2}{|c|}{ Men }} & \multicolumn{4}{|c|}{ Currently Married } \\
\hline & & & & & \multicolumn{2}{|c|}{ Women } & \multicolumn{2}{|l|}{ Men } \\
\hline & IFS $=1$ & $\mathbf{N}$ & IFS $=1$ & $\mathbf{N}$ & IFS $=1$ & $\mathbf{N}$ & IFS $=1$ & $\mathbf{N}$ \\
\hline India & 17 & 25,462 & 13.9 & 25,383 & 6.4 & 93,088 & 6.4 & 47,875 \\
\hline \multicolumn{9}{|l|}{ Age } \\
\hline$<30$ years & 16.8 & 24,783 & 13.4 & 23,946 & 7.1 & 42,049 & 6.1 & 11,713 \\
\hline $30+$ years & 22.4 & 679 & 21.4 & 1,437 & 5.9 & 51,041 & 6.5 & 36,162 \\
\hline \multicolumn{9}{|l|}{ Place of Residence } \\
\hline Urban & 24.5 & 10,327 & 18.4 & 10,851 & 10.7 & 28,604 & 9.3 & 16,021 \\
\hline Rural & 11.9 & 15,135 & 10.5 & 14,530 & 4.5 & 64,485 & 5.0 & 31,854 \\
\hline \multicolumn{9}{|l|}{ Wealth Index } \\
\hline Poorest & 4.5 & 2,964 & 4.4 & 2,791 & 2.0 & 17,425 & 1.7 & 8,589 \\
\hline Poorer & 8.8 & 3,855 & 7.1 & 3,994 & 3.4 & 18,494 & 3.1 & 9,198 \\
\hline Middle & 11.7 & 5,097 & 10.4 & 5,206 & 4.8 & 18,671 & 5.3 & 9,764 \\
\hline Richer & 17.0 & 6,015 & 15.8 & 6,302 & 7.3 & 18,985 & 7.5 & 9,982 \\
\hline Richest & 29.7 & 7,532 & 22.1 & 7,090 & 13.9 & 19,513 & 13.1 & 10,341 \\
\hline \multicolumn{9}{|l|}{ Caste } \\
\hline Schedule Caste & 14.7 & 4,388 & 11.8 & 4,631 & 4.3 & 17,372 & 4.9 & 9,077 \\
\hline Schedule Tribe & 6.9 & 1,926 & 6.6 & 1,645 & 2.9 & 7,631 & 2.3 & 4,259 \\
\hline Other Backward Classes & 14.8 & 9,579 & 13.1 & 9,699 & 4.9 & 37,198 & 5.5 & 18,956 \\
\hline Other & 23.2 & 8,740 & 17.7 & 8,517 & 10.7 & 28,174 & 9.8 & 14,085 \\
\hline
\end{tabular}

Religion 


\begin{tabular}{lllllllll} 
Hindu & 19.1 & 19,626 & 15.1 & 20,460 & 7.0 & 75,799 & 6.8 & 39,591 \\
Muslim & 6.7 & 3,932 & 4.7 & 3,379 & 2.4 & 12,289 & 3.2 & 5,724 \\
Christian & 12.7 & 842 & 15.3 & 608 & 5.9 & 2,040 & 4.4 & 1,052 \\
Sikh & 21.6 & 569 & 19.9 & 523 & 13.1 & 1,567 & 12.0 & 822 \\
Other & 17.9 & 476 & 16.0 & 407 & 5.7 & 1,297 & 6.1 & 677 \\
Education & & & & & & & & \\
No education & 3.5 & 3,203 & 4.5 & 1,965 & 2.3 & 43,931 & 1.9 & 11,438 \\
$<5$ years completed & 8.8 & 769 & 3.8 & 869 & 4.4 & 4,250 & 3.3 & 3,620 \\
5-7 years completed & 8.1 & 4,675 & 6.5 & 4,647 & 5.7 & 17,413 & 4.1 & 10,370 \\
8-9 years completed & 15.0 & 6,168 & 11.0 & 6,723 & 9.2 & 10,735 & 6.7 & 8,117 \\
10-11 years completed & 20.6 & 4,921 & 17.8 & 5,187 & 12.6 & 7,704 & 9.5 & 5,707 \\
12 or more years completed & 31.9 & 5,715 & 23.9 & 5,954 & 20.3 & 8,921 & 14.4 & 8,449 \\
\hline
\end{tabular}

Source: NFHS-3, 2005-06

There are, however, high degrees of variation in ideal family sizes across India's 29 states. As Table 4 demonstrates, the scope of one-child ideation ranges from 33.4 per cent in Himachal Pradesh down to 0.7 per cent in Mizoram. Sikkim, Tripura, West Bengal, Karnataka, Delhi, Maharashtra, Goa, Punjab, and Kerala are some of the states which show high prevalence of one-child family ideation.

Table 4: Percentage of never married and currently married women (15-49) and men $(15-54)$ with IFS=1 by state

\begin{tabular}{|c|c|c|c|c|c|c|c|c|}
\hline & \multicolumn{4}{|c|}{ Never Married } & \multicolumn{4}{|c|}{ Currently Married } \\
\hline & \multicolumn{2}{|c|}{ Women } & \multicolumn{2}{|l|}{ Men } & \multicolumn{2}{|c|}{ Women } & \multicolumn{2}{|l|}{ Men } \\
\hline & IFS $=1$ & $\mathbf{N}$ & IFS $=1$ & $\mathbf{N}$ & IFS=1 & $\mathbf{N}$ & IFS $=1$ & $\mathbf{N}$ \\
\hline India & 17 & 25,460 & 13.9 & 25,382 & 6.4 & 93,091 & 6.4 & 47,875 \\
\hline Himachal Pradesh & 33.4 & 815 & 29.8 & 410 & 12.4 & 2,278 & 10.6 & 649 \\
\hline Sikkim & 33.0 & 669 & 15.8 & 318 & 20.4 & 1,374 & 10.7 & 467 \\
\hline Tripura & 32.1 & 448 & 18.6 & 275 & 17.7 & 1,338 & 15.2 & 432 \\
\hline West Bengal & 31.1 & 1,151 & 23.7 & 886 & 14.6 & 5,234 & 14.7 & 1,752 \\
\hline Karnataka & 29.3 & 1,290 & 21.6 & 2,046 & 11.5 & 4,347 & 9.1 & 3,437 \\
\hline Delhi & 26.1 & 901 & 15.9 & 632 & 8.8 & 2,351 & 7.2 & 792 \\
\hline Tamil Nadu & 25.8 & 1,316 & 23.2 & 2,025 & 9.3 & 4,179 & 11.5 & 3,602 \\
\hline Maharashtra & 22.9 & 1,943 & 18.8 & 3,402 & 7.1 & 6,606 & 8 & 5,391 \\
\hline
\end{tabular}




\begin{tabular}{|c|c|c|c|c|c|c|c|c|}
\hline Orissa & 21.4 & 1,068 & 22.8 & 518 & 7.3 & 3,292 & 8.1 & 1,041 \\
\hline Goa & 20.4 & 1,167 & 12.0 & 516 & 11.9 & 2,143 & 10.8 & 663 \\
\hline Gujarat & 18.5 & 769 & 13.5 & 436 & 7.7 & 2,828 & 4.9 & 964 \\
\hline Punjab & 18.4 & 924 & 16.2 & 505 & 10.4 & 2,634 & 8.7 & 808 \\
\hline Haryana & 17.0 & 542 & 18.4 & 386 & 6.3 & 2,131 & 7.2 & 687 \\
\hline Uttaranchal & 15.6 & 778 & 15.6 & 360 & 6.4 & 2,078 & 7.5 & 618 \\
\hline Assam & 14.3 & 972 & 8.1 & 569 & 8.2 & 2,656 & 5.4 & 805 \\
\hline Andhra Pradesh & 13.7 & 1,168 & 13.9 & 2,112 & 5.0 & 5,466 & 5.9 & 4,930 \\
\hline Jharkhand & 11.7 & 509 & 8.0 & 293 & 3.9 & 2,336 & 2.2 & 687 \\
\hline Madhya Pradesh & 11.6 & 1,140 & 9.3 & 809 & 3.3 & 5,020 & 2.7 & 1,845 \\
\hline Kerala & 10.3 & 796 & 8.5 & 437 & 4.7 & 2,617 & 4.8 & 675 \\
\hline Uttar Pradesh & 9.6 & 2,696 & 5.6 & 4,038 & 3.6 & 9,134 & 3.4 & 7,167 \\
\hline Rajasthan & 9.4 & 677 & 5.5 & 427 & 3.1 & 3,065 & 2.3 & 1,026 \\
\hline Chhattisgarh & 8.1 & 806 & 6.9 & 406 & 2.4 & 2,752 & 2.1 & 950 \\
\hline Bihar & 7.8 & 599 & 6.2 & 353 & 1.6 & 3,091 & 3.6 & 839 \\
\hline Jammu and Kashmir & 7.0 & 1,161 & 7.1 & 505 & 4.5 & 2,045 & 4.2 & 555 \\
\hline Arunachal Pradesh & 2.9 & 454 & 3.1 & 264 & 3.5 & 1,128 & 1.9 & 429 \\
\hline Manipur & 2.1 & 1,628 & 3.1 & 1,663 & 1.9 & 2,681 & 2.3 & 2,241 \\
\hline Nagaland & 1.8 & 1,378 & 2.2 & 1,796 & 2.0 & 2,354 & 1.9 & 2,118 \\
\hline Meghalaya & 1.8 & 729 & 2.2 & 328 & 1.1 & 1,212 & 1.0 & 380 \\
\hline Mizoram & 0.7 & 593 & 0.4 & 270 & 0.1 & 1,054 & - & 371 \\
\hline
\end{tabular}

Source: NFHS-3, 2005-06

In conclusion, therefore, a significant number of women (and men) in India view their personal ideal family size as including just one child. As would match our a priori expectations, there is a very wide degree of heterogeneity both between states and by socioeconomic status. However, there are important deliberations to be made before pronouncing the importance or strength of these observations. The first exploration is broadly statistical in nature, in that there is a clear need to move beyond the descriptive statistics and to test the robustness of these findings in a regression context. A multivariate logistic regression model of the determinants of having a one-child family ideal was performed on the NFHS-3 data. The logistic regression model confirms a number of expected features: that women with two or more children generally do not hypothetically wish for one child and that 
one-child family ideation is positively associated with increased education, wealth, and urban residence. $^{2}$

The second major concern regarding India as raised by the discussion above concerns the strength of measuring 'ideal family size' as a concept in itself. Fortunately, NFHS-3, 2005-06, provides a set of questions that help to identify married couples who have reached their desired maximum number of children. If a (married) woman was not pregnant or not sure of pregnancy, the following question was asked: "Would you like to have a child or would you prefer not to have any children?" Meanwhile, for (married) pregnant women the question was: "After the child expected now, would you like to have another child, or would you prefer not to have any more children?" We can therefore use these questions to explore what might be termed the 'operationalization' of a one-child ideal. As such, three dichotomous indicators have been generated. The first $\left[O C_{\text {stop }}\right]$ measures the percentage of non-pregnant currently married women who have one surviving child and they do not want more children (i.e. a desire to 'stop' childbearing). The second $\left[O C_{F P}\right]$ measures the percentage of currently married women with one surviving child, who do not want more children and are using any family planning method. Finally, the third $\left[O C_{s t e r}\right]$ gives the percentage of currently married women having one surviving child, and who are sterilized.

Table 5 shows the prevalence of one-child families as measured by these three indicators of one-child family by different socioeconomic characteristics. Only 4.7 per cent of women have one child and want to stop childbearing, with only 2.9 per cent of women with one child both desiring to stop childbearing and using family planning. (Just 1 per cent of women with one child become sterilized to prevent future pregnancies.) In other words, this 4.7 per cent of women in category $O C_{F P}$ have an unmet need for family planning. However, Table 5 also shows a very high degree of heterogeneity, with urban women twice as likely as their rural counterparts to intend to stop childbearing at one child, and the richest and best educated more than four times more likely than the poorest and unschooled. In order to better explore the predictors of such 'stopping' behaviour, an improved set of variables is required. This is available in the Indian Human Development Survey, which is explored in the following section.

Table 5: Percentage of currently married women in age group 15-49 with one-child family by selected characteristics

\footnotetext{
${ }^{2}$ Regression results not shown here, but are available from the author on request.
} 


\begin{tabular}{|c|c|c|c|c|}
\hline & \multicolumn{4}{|c|}{ Percent Women } \\
\hline & $O C_{\text {stop }}$ & $O C_{F P}$ & $O C_{\text {ster }}$ & $\mathbf{N}$ \\
\hline India & 4.7 & 2.9 & 1.0 & 93,088 \\
\hline \multicolumn{5}{|l|}{ Age } \\
\hline$<30$ years & 4.6 & 2.6 & 0.5 & 42,049 \\
\hline $30+$ years & 4.9 & 3.0 & 1.4 & 51,041 \\
\hline \multicolumn{5}{|l|}{ Place of Residence } \\
\hline Urban & 7.4 & 4.7 & 1.0 & 28,604 \\
\hline Rural & 3.6 & 2.0 & 1.0 & 64,485 \\
\hline \multicolumn{5}{|l|}{ Wealth Index } \\
\hline Poorest & 2.3 & 1.1 & 0.9 & 17,425 \\
\hline Poorer & 2.8 & 1.6 & 0.9 & 18,494 \\
\hline Middle & 3.8 & 2.0 & 1.2 & 18,671 \\
\hline Richer & 4.9 & 2.9 & 1.0 & 18,985 \\
\hline Richest & 9.6 & 6.4 & 1.0 & 19,513 \\
\hline \multicolumn{5}{|l|}{ Caste } \\
\hline Schedule Caste & 3.0 & 1.8 & 1.2 & 17,372 \\
\hline Schedule Tribe & 3.6 & 1.9 & 1.0 & 7,631 \\
\hline Other Backward Classes & 7.4 & 4.8 & 1.0 & 37,198 \\
\hline Other & 6.1 & 3.3 & 1.6 & 28,174 \\
\hline \multicolumn{5}{|l|}{ Religion } \\
\hline Hindu & 5.1 & 3.1 & 1.1 & 75,799 \\
\hline Muslim & 2.1 & 1.1 & 0.4 & 12,289 \\
\hline Christian & 5.8 & 3.2 & 1.5 & 2,040 \\
\hline Sikh & 8.6 & 6.1 & 0.4 & 1,567 \\
\hline Other & 4.3 & 2.5 & 0.7 & 1,297 \\
\hline \multicolumn{5}{|l|}{ Education } \\
\hline No Education & 2.4 & 1.3 & 1.0 & 7,776 \\
\hline$<5$ years completed & 3.8 & 2.3 & 1.3 & 14,018 \\
\hline 5-7 years completed & 4.2 & 2.4 & 1.2 & 17,413 \\
\hline $8-9$ years completed & 5.8 & 3.5 & 0.7 & 10,735 \\
\hline 10-11 years completed & 8.1 & 4.9 & 1.0 & 7,704 \\
\hline 12 or more years completed & 5.8 & 3.5 & 0.7 & 8,921 \\
\hline
\end{tabular}

Source: NFHS-3, 2005-06 
Notes: $O C_{\text {stop }}=$ women with one child who state an intention to stop childbearing; $O C_{F P}=$ women with one child using family planning methods; $O C_{\text {ster }}=$ women with one child who have been sterilized. 
As well as heterogeneity by social and economic characteristics, there are also high degrees of variation between Indian states. As Table 6 demonstrates, Tripura, Sikkim, and West Bengal all see the number of married women who wish to limit their future childbearing at parity one being over 10 per cent.

Table 6: Percentage of currently married women in age group 15-49 with one-child family by state

\begin{tabular}{|c|c|c|c|c|}
\hline & \multicolumn{4}{|c|}{ Percent Women } \\
\hline & $O C_{\text {stop }}$ & $O C_{F P}$ & $O C_{\text {ster }}$ & $\mathbf{N}$ \\
\hline India & 5.0 & 2.9 & 0.9 & 93,091 \\
\hline Tripura & 14.4 & 10.0 & 0.9 & 1,338 \\
\hline Sikkim & 14.0 & 8.0 & 0.5 & 1,374 \\
\hline West Bengal & 10.9 & 8.4 & 1.0 & 5,234 \\
\hline Goa & 8.5 & 3.4 & 0.8 & 2,143 \\
\hline Tamil Nadu & 7.4 & 3.3 & 2.0 & 4,179 \\
\hline Assam & 7.1 & 4.7 & 0.3 & 2,656 \\
\hline Karnataka & 7.0 & 3.7 & 2.4 & 4,347 \\
\hline Orissa & 6.8 & 3.6 & 1.5 & 3,292 \\
\hline Punjab & 6.6 & 4.5 & 0.4 & 2,634 \\
\hline Delhi & 6.6 & 5.0 & 0.5 & 2,351 \\
\hline Himachal Pradesh & 6.5 & 3.8 & 1.3 & 2,278 \\
\hline Maharashtra & 5.5 & 3.2 & 1.2 & 6,606 \\
\hline Kerala & 5.4 & 3.2 & 0.8 & 2,617 \\
\hline Gujarat & 4.7 & 3.0 & 0.9 & 2,828 \\
\hline Andhra Pradesh & 4.3 & 3.0 & 2.8 & 5,466 \\
\hline Haryana & 4.0 & 2.3 & 0.3 & 2,131 \\
\hline Uttaranchal & 3.5 & 1.4 & 0.3 & 2,078 \\
\hline Arunachal Pradesh & 3.5 & 1.2 & 0.5 & 1,128 \\
\hline Nagaland & 3.0 & 1.0 & - & 2,354 \\
\hline Jharkhand & 2.7 & 1.3 & 0.4 & 2,336 \\
\hline Chhattisgarh & 2.7 & 1.2 & 0.9 & 2,752 \\
\hline Madhya Pradesh & 2.6 & 1.6 & 1.0 & 5,020 \\
\hline Manipur & 2.5 & 1.2 & - & 2,681 \\
\hline Jammu and Kashmir & 2.2 & 0.9 & 0.1 & 2,045 \\
\hline Rajasthan & 2.1 & 1.0 & 0.6 & 3,065 \\
\hline Uttar Pradesh & 2.0 & 1.0 & 0.3 & 9,134 \\
\hline
\end{tabular}




\begin{tabular}{lllll} 
Bihar & 1.6 & 0.5 & 0.3 & 3,091 \\
Mizoram & 1.6 & 1.6 & 1.6 & 1,054 \\
Meghalaya & 1.1 & 0.5 & 0.1 & 1,212 \\
\hline
\end{tabular}

Source: NFHS-3, 2005-06

Notes: $O C_{\text {stop }}=$ women with one child who state an intention to stop childbearing; $O C_{F P}=$ women with one child using family planning methods; $O C_{\text {ster }}=$ women with one child who have been sterilized.

What this evidence suggests is that there may well be a sizeable gap between an ideation of a one-child family and its operationalization in India. In order to attempt to explain this, a much deeper understanding of the changing nature of the family and childbearing in India must be undertaken. A wide body of literature has identified the key role which India's comprehensive family planning policy has played in shaping recent trajectories (Banerji, 1992; Jiang \& Hardee, 2014; Rajan \& Padmavathi, 1990; Rao, 2003; Santhya, 2003; Srinivasan, 1983; Williams, 2014).

The fact that such significant numbers of respondents feel that, in some way, limiting childbearing to just one child is surely of note. Of special interest are the preferences of those who might be considered to be in the 'vanguard' of not just fertility transition, but also economic and social development. In other words, as more of India's population urbanize, become better educated and (perhaps) better share in the developing wealth of the country, could the number of people with an idealized family size of just one increase? And could this then translate into actuality with increasing numbers of one-child families? A critical research development will occur sometime between 2015 and 2016, when the fourth National Family Health Survey will be released (being run 2014-16). Given that the relevant questions are the same, this added point of reference will help to further identify patterns of change in onechild ideation in India.

\section{Exploring one-child ideation in India}

The evidence from certain cities and regions, and West Bengal in particular, seems to suggest that the one-child family is a relevant component of the demographic landscape of certain parts of India. Furthermore, the remarkable findings in the previous section regarding the ideation of one-child families by significant proportions of unmarried, younger (and 
especially urban, more educated) Indians means that a closer examination of the context of the one-child family in India is justifiable. However, in the same way that China is often examined separately from elsewhere in Pacific Asia in terms of the drivers of low fertility, so are the geographical and societal 'parts' of India which, it can be argued, are also characterized by low(er) fertility. In this section we will review the literature on the context and drivers of one-child ideation in India, exploring the extent to which there are differences and similarities to the other settings examined in this paper.

Earlier in this paper, we identified a hierarchy of rural-urban differentials in recorded one-child families, with a disproportionately higher preponderance in 'metropolitan areas', as well as identifying the presence of extremely low fertility rates in Kolkata, Chennai, Mumbai, and some other Indian cities. Indeed, the process of urbanization in India since the 1960s, while lagging behind China, has been phenomenal (Datta, 2006). The vast majority of urban growth has been in larger urban settlements like cities rather than in small towns (Datta, 2006). Indeed, as Revi (2008) observes, over the next 40 years, India will experience one of the most dramatic settlement transitions in history, as its urban population should grow from about 300 million to more than 700 million.

However, the process of urbanization and its relationship to pushing down fertility in India is by no means a simple and unidirectional one. The relationship between urbanization and fertility decline is often theorized as being driven by increased wealth but offset against higher costs of childbearing. Implicit in this is a sense of a pull factor of towns and cities and migrants' roles in offsetting childbearing to better take advantage of these urban opportunities (Mace, 2008). Yet, the pattern of urbanization in India has seen rather a different pattern, with Breese's 1969 observation that urbanization in India was better characterized as 'pseudo-urbanization' and the primary role of poverty induced rural 'push' rather than urban 'pull' simply leading to the relocation of the poor (Breese, 1969). Indian urbanization is therefore often characterized as a lopsided, dysfunctional process (Premi, 1991) with extreme infrastructure problems (Kundu, Bagchi, \& Kundu, 1999); extremely high levels in insecure/inadequate informal labour (Kundu, Lalitha, \& Arora, 2001) and generally poor conditions. Yet given that slum fertility is invariably higher than non-slum fertility in India (Narayan, 2011), and from the evidence of a positive relationship between one-child ideation and wealth/education shown elsewhere, we cannot simply assume a simple, unidirectional poverty-induced driver behind the increase in one-child families (i.e., that couples simply can only afford to have one child net of all other expenditures). 
On the other hand, to return again to a theme discussed elsewhere in the literature, are we seeing the playing out of the 'competing goods hypothesis' where the neoliberal city economy offers 'the largest and most seductive non-material alternatives to children... alternatives moreover that require one to be unfettered by children if one is to really exploit them' (Basu \& Desai, 2012, p. 20)? These can either be explicitly focused on consumption, or more geared towards personal aspiration. Again, to return to Easterlin's (1966) hypothesis and the Chicago-Columbia model of competition between childbearing and consumption, we might expect a refocus on consumption expenditure in the context of either poor economic conditions or higher aspirations. This links back to the 'post-modern' values described by Van de Kaa (2001) within a Second Demographic Transition [SDT] framework. While universal marriage in India arguably negates the validity of the SDT argument concerning the striving for personal expression and individualization - at least in the case of the marriage market - could there still be a link towards the striving for more higher-order Maslowian needs and one-child families and their ideation? Part of this view in India can be traced back to early domestic manuals, which, have been suggested, emphasize the marital over the maternal bond (Walsh, 2005).

In online forums and discussions concerning articles about the growth in prevalence and ideation of one-child families in India, it is this 'competing goods hypothesis' framework that seems to influence the views of a majority of contributors. 'Injustice destroyer', commenting on an online piece in the Hindustan Times, for example, states that 'Parents should not be so selfish and egoistic that they would rather care about their own desires instead of giving their children many to grow up with. Anything is better than being an only child' (Khanna, 2009). The logical extension of this is the remark by 'Suraj', writing in a Good Housekeeping India forum, that 'Childfree is the best policy... Then couples will have no financial problems and also be tension free' (Good Housekeeping, 2014). Indeed, 'Suraj's' point neatly addresses these twin foci of the 'competing goods' hypothesis - namely a preponderance towards higher consumption orientations and a greater investment in personal aspirations.

Fortunately, the Indian Human Development Survey allows for a closer investigation of any possible linkages between one-child family status and a broad 'competing goods' hypothesis based around 'postmodern' fertility preferences. Returning to Basu and Desai's landmark study, they first consider ownership of a set of 23 assets and amenities and, indeed, find higher asset ownership among one-child families - likely because of their concentration among higher income groups. However, when holding income and education constant, the 
magnitude of this difference becomes very small. Indeed, when further restricting asset ownership to 'major' goods such as a car, washing machine, air conditioner, and computer, the difference becomes 'minuscule' for rural areas and remains 'very small' for urban areas. This leads Basu and Desai to conclude that 'small families, particularly one-child families, are not substantially more consumption focused than larger families' (p. 17).

Basu and Desai then proceed to explore personal aspirations as a possible driver for one-child families, by examining four potentially relevant indicators: hours of television watched per day by women; whether the respondent and her husband go out to watch films or to fairs/festivals with or without children, but without other extended family members; an index measuring frequency of discussion between the couple about politics, community events, farm issues, household expenditure, etc.; and finally whether the respondent is able to visit her natal family at least once a month. They find that while education and income have the expected relationship with these indicators of personal freedom and expression, having one child does not result in a greater amount of personal freedom or conjugal intimacy. (Indeed, they find that having more than one child is linked to greater couple communication.) While recognizing the potential superficiality of these measures, Basu and Desai tentatively conclude that 'in none of these four markers do we see a large and substantial improvement in personal freedom' linked to smaller families. In sum, therefore, their study finds 'only a minor relationship between family size and markers of personal consumption or personal fulfilment' (p. 23).

A further construction which has been explored elsewhere concerns the potential role of female labour force participation, which has changed remarkably over recent decades as a result of a combination of economic imperative, economic restructuring, and improved education and rights (Ramanna \& Bombawale, 1984; Srivastava, 1978). Rather than purely levels of labour force participation, it is perhaps more significant to note the major shift in the nature of women's work, and the move from home-based work that might be more compatible with fertility (Jaffe \& Azumi, 1960) towards work for pay (usually) outside of the house (Mason \& Palan, 1986). Returning to Gerson (1986), when faced with demands of childrearing and work, women may choose to limit the former to satisfy their demands for children while limiting the demands of family on their time (Basu \& Desai, 2012 p. 14). In this context, a growing literature has identified similar characteristics in India relating to work-life balance and conflicts therein as seen elsewhere (Chandra, 2010; Kaur, De, \& Ranjan, 2013; Reddy, Vranda, Ahmed, Nirmala, \& Siddaramu, 2010). 
Again, turning to the Human Development Survey, Basu and Desai (2012) perform a logistic regression analysis for predicting the probabilities of family size on both work in general (including work in a family business or on farms) as well as paid work. Contrary to expectations, perhaps, they find that for both types of work 'women with a single child are actually less likely to be employed than women with larger families' (p. 14). As such, they conclude that neither 'role incompatibility' nor a 'higher commitment to the work force' appears to be a 'motivating factor for women to have very low fertility' (p. 15).

The final potential motivating factor considered by Basu and Desai $(2012$, p. 7) is 'investing in children', or 'low fertility as a route to social mobility'. We have already discussed earlier the remarkable changes in education provision and the potential to leverage individual training in the labour market. Other studies have identified strong evidence for a desire to maximize investment in developing the education and skills of a smaller number of children for social, cultural or economic reasons, possibly set in the context of (generational) social mobility. Indeed, in the context of globalization, liberalization, and privatization, however, opportunities generally only accrue to those who are able to acquire new skills (Despande and Despande, 1998).

Again turning to the Human Development Survey, this time Basu and Desai (2012) were able to present much more clear-cut conclusions. Analyzing educational expenditure for more than 30,000 children aged 6-14, after controlling for parental characteristics, child's gender and age, they found that there was, indeed, 'a striking impact of family size on educational investments' (p. 22). The importance of the results mean that they should be reproduced in full: 'Expenditures on children's education is higher by 40 per cent in onechild families than in families with three or more children; two-child families fall in between. Children from one-child families are 1.56 times as likely to be in a private school as children from $3+$ child families, while children from two-child families are 1.4 times as likely to attend private school. Both of these relationships are significant at the 0.001 percent level' ( $\mathrm{p}$. 22).

Basu and Desai conclude that 'rather than placing a greater value on parental desires and freedoms' the focus of parents appears to be more grounded in 'investing in this single child' (pp. 23-24). They suggest that such children who receive these advanced educational opportunities are 'certainly more suited to take advantage of new opportunities in the economy' and, in doing so, stand a better chance of 'fulfilling the ever more ambitious dreams of social and economic mobility in the [Indian] middle classes' (pp. 24-25). Indeed, Professor Saswata Ghosh of the Kolkata Institute of Development Studies has suggested that 
the very low fertility rates seen in that city (of around 1.4) could indeed be due to a 'qualityquantity trade off' where couples 'would much rather have one child and give him or her the best education and facilities they can afford, rather than spread resources thinly between two children or more' (cited in Livemint, 2015). Crucially, he notes that - at least from his research in Kolkata - 'the reluctance to have more than one child is not restricted to the urban elite'. Elsewhere, a study which explored the motivations for women to take on wage labour noted that women, 'especially those from the lower middle class, are seeking the job market today because they have to augment the family income. They have to provide a better life for their families, pay their children's tuition fees and plan a better future for them' (Reddy et al., 2010, p. 117).

Clearly, much more research should be performed on the underlying drivers behind the growth in prevalence and ideation of one-child families in India. For a start, qualitative studies of the phenomenon are almost entirely lacking. Such studies, combined with analysis of micro-level data and regional studies, will surely lead to a heightened understanding of what could be an important future trend in Indian demography.

But the evidence presented here for India suggests that there are clearly similarities in terms of the landscape of one-child ideation which we see developing in India, compared to what we have seen in recent decades as key drivers elsewhere in low-fertility Asia. The evidence presented by Basu and Desai appears to debunk this (popular) notion that couples who idealize a one-child family are more inherently consumption-oriented. Rather, the evidence seems to suggest a desire to invest the maximum possible in as few children as possible for their sake, rather than for the gratification of parents. In terms of the competing risks which decisions regarding childbearing inevitably draw together, we must observe the risks of childbearing in any society, especially regarding financial costs and, within the individualization framework, the capacity for men (and especially women) to 'build a life of their own'. This link to the 'individualization' hypothesis as discussed by Beck and BeckGernsheim (2002) may seem farfetched (as it has been so little considered outside Europe, let alone in the Global South), but it again seems to suggest that similarities between the potential future of fertility in India and the recent past of other settings in Asia can be more readily justified, even if many of the institutional, political, religious, and economic frameworks are very different. Indeed, in this context the same argument can likely be made for other 'transition' settings such as Nepal and Bangladesh, both of which have seen dramatic investment in education in recent years. 
We can also consider the notion that parents feel an obligation to give their children the best possible opportunity to navigate Beck's (1992) 'risk society' and 'build a life of their own' in the future. Furthermore, again in settings characterized by poor institutional support for old age, the decision to invest heavily in one child may yield longer term dividends.

\section{References}

Banerji, D. (1992). Family Planning in the Nineties: More of the Same? Economic and Political Weekly, 27(17), 14-24.

Basu, A. M., \& Desai, S. B. (2012). Middle Class Dreams: India's One-Child Families. Conference paper presented at IUSSP Conference, Busan 2012.

Beck, U. (1992). Risk Society: Towards a New Modernity. London: Sage.

Beck, U., \& Beck-Gernsheim, E. (2002). Individualization. Institutionalized Individualism and its Social and Political Consequences. London: Sage.

Bhat, P. N. M. (1996). Contours of Fertility Decline in India: A District Level Study Based on the 1991 Census. In K. Srinivasan (ed.), Population Policy and Reproductive Health. New Delhi: Hindusthan Publishing Corporation, pp. 96-117.

Breese, G. (1969). Urbanisation in Newly Developing Countries. New Delhi: Prentice Hall. Chandra, V. (2010). Women and Work-Family Interface: Indian Context. Journal of Asia Pacific Studies, 1(2), 235-258.

Datta, P. (2006). Urbanisation in India. Paper presented at European Population Conference, Liverpool 2006.

Easterlin, R. A. (1966). On Relation of Economic Factors to Recent and Fertility Changes. Demography, 3(1), 131-151.

Gerson, K. (1986). Hard Choices: How Women Decide about Work, Career, and Motherhood. Berkeley, CA: University of California Press.

Good Housekeeping. (2014). Is it OK to Have a Single Child? Good Housekeeping India. Retrieved from https://sg.finance.yahoo.com/news/is-it-ok-to-have-a-single-child103845627.html June 13th 2017 
Guilmoto, C. Z., \& Rajan, S. I. (2013). 'Fertility at District Level in India: Lessons from the 2011 Census', Working Papers du CEPED, June 2013 (30)

Jaffe, A. J., \& Azumi, K. (1960). The Birth Rate and Cottage Industries in Underdeveloped Countries. Economic Development and Cultural Change, 9(1), 52-63.

Jiang, L., \& Hardee, K. (2014). Women's Education, Family Planning, or Both? Application of Multistate Demographic Projections in India. International Journal of Population Research Article ID 940509, 9 pages

Kaur, A. P., De, K. K., \& Ranjan, T. M. (2013). Impact of Work and Family Role Demands on Work Life Conflict amongst Working Woman. Indian Journal of Applied Research, 3(8) $23-55$.

Khanna, P. (2009). Why are Indian families shrinking? Hindustan Times Retrieved 25 January 2015 from: http://www.hindustantimes.com/sexandrelationships/why-are-indianfamilies-shrinking/article1-471292.aspx

Kundu, A., Bagchi, S., \& Kundu, D. (1999). Regional Distribution of Infrastructure and Basic Amenities in Urban India - Issues Concerning Empowerment of Local Bodies. Economic and Political Weekly, 34(28), 1893-1906.

Kundu, A. \& Sharma, A.N. (2001). Growth Dynamics of Informal Manufacturing Sector in Urabn India: An Analysis of Interdependence. In A. Kunda \& A. N. Sharma (eds.), Informal Sector in India. New Delhi: Institute of Human Development, and Institute of Applied Manpower Research

Livemint. (2015). Falling total fertility rate in Kolkata sets alarm bells ringing. Retrieved 25 January 2015 from: http://www.livemint.com/Politics/9jV7AFSSMgeCrJqyPgNwFI/Fallingtotal-fertility-rate-in-Kolkata-sets-alarm-bells-rin.html

Mace, R. (2008). Reproducing in cities. Science, 319(5864), 764-6.

Mason, K. O., \& Palan, V. T. (1986). Female Employment and Fertility in Peninsular Malaysia: The Maternal Role Incompatability Hypothesis Reconsidered. Demography, 18(4), $549-575$. 
Narayan, R. (2011). Contraceptive Use among Slum and Non-Slum Dwellers: Analysis of Selected Cities in India. Paper presented at PAA Annual Meeting, Washington D.C. 2011. Retrieved 25 January2015 from: http://paa2011.princeton.edu/papers/111065

Pradhan, I., \& Sekher, T. V. (2014). Single-child families in India: Levels, trends and determinants. Asian Population Studies, 10(2), 163-175.

Premi, M. K. (1991). India's Urban Scene and its Future Implications. Demography India, 20(1).

Rajan, I., \& Padmavathi, R. (1990). India's Family Planning Programme: A Critical Approach. Economic Journal of Nepal, 13, 21-42.

Ramanna, A., \& Bombawale, U. (1984). Transitory Status Images of Working Women in Modern India. Indian Journal of Social Work, 45, 189-202.

Rao, M. (2003). Two-Child Norm and Panehayats: Many Steps Back. Economic and Political Weekly, 38(33), 3452-3454.

Reddy, N. K., Vranda, M. N., Ahmed, A., Nirmala, B. P., \& Siddaramu, B. (2010). WorkLife Balance among Married Women Employees. Indian Journal of Psychological Medicine, 32(2), 112-8. https://doi.org/10.4103/0253-7176.78508

Revi, A. (2008). Climate Change Risk: An Adaptation and Mitigation for Indian Citizens. Environment \& Urbanization, 20(1), 207-229.

Santhya, K. (2003). Changing Family Planning Scenario in India: An Overview of Recent Evidence (Population Council Regional Working Papers [South \& East Asia] No. 17). New Delhi: Population Council.

Sen, S. (2012). Where have Bengal's babies gone? Times of India Retrieved 2 February2015 from: http://timesofindia.indiatimes.com/city/kolkata/Where-have-Bengals-babiesgone/articleshow/12617632.cms

Senthil Velou, M., Senthamizselvi, K., Teli, S., Soundarya, K., \& Thendral, V. (2014). Prevalence of Single Child (Individuals without Siblings) in Our Society: A Cross-Sectional Study from Puducherry. Scholars Journal of Applied Medical Science, 2(4A), 1206-1209. 
Srinivasan, K. (1983). India’s Family Planning Programme: Its Impacts and Implications. Journal of Family Welfare, 30(2), 7-25.

Srivastava, V. (1978). Employment of Educated Women in India; its Causes and Consequences. New Delhi: National Publishing House.

Van de Kaa, D. J. (2001). Postmodern Fertility Preferences: From Changing Value Orientation to New Behavior. Population \& Development Review, 27 (supplement), 290-331.

Walsh, J. E. (2005). How to be Goddess of Your Home: An Anthology of Bengali Domestic Manuals. New Delhi: Yoda Press.

Williams, R. J. (2014). Storming the Citadels of Poverty: Family Planning under the Emergency in India, 1975-1977. The Journal of Asian Studies, 73(2), 471-492. 
